\title{
DIAGNÓSTICO DAS ÁREAS DE PRESERVAÇÃO PERMANENTE NA BACIA HIDROGRÁFICA DO RIO TIJUCO, ITUIUTABA - MG, UTILIZANDO TECNOLOGIA SIG
}

\author{
RENATO F. DO VALLE JÚNIOR ${ }^{1}$, TERESA C. T. PISSARRA ${ }^{2}$, ANDRÉA DE O. PASSOS ${ }^{3}$, \\ TIAGO G. RAMOS ${ }^{3}$, VERA L. ABDALA ${ }^{4}$
}

RESUMO: O presente trabalho teve como objetivo elaborar o mapa de uso da terra e cobertura vegetal da bacia hidrográfica do Rio Tijuco, município de Ituiutaba - MG, com base nas imagens digitais obtidas do satélite CBERS 2, através de delimitação automática das áreas de preservação permanente, seguindo-se a identificação de ocorrência de conflito de uso, tendo como referência legal o Código Florestal Brasileiro (Lei $n^{\circ}$. 4.771/1965) e a resolução $n^{0}$ 303/02, do Conselho Nacional do Meio Ambiente. Este artigo analisa, por meio de parâmetros quantitativos e uso do Sistema de Informação Geográfica, a manutenção de faixas de preservação permanente de larguras recomendadas pela legislação ao longo dos corpos d'água. Os resultados mostraram um déficit de áreas preservadas às margens dos rios de 2.334 ha, que não estão em conformidade com a legislação. A pastagem ocupa, indevidamente, $0,97 \%$ da área da bacia nas áreas de preservação permanente às margens dos rios, enquanto a agricultura ocupa $0,38 \%$.

PALAVRAS-CHAVE: reserva legal, geoprocessamento, uso da terra, sensoriamento remoto.

\section{DIAGNOSIS OF AREAS OF PERMANENT PRESERVATION AT THE TIJUCO RIVER WATERSHED, ITUIUTABA - MG, BRAZIL, USING GIS TECHNOLOGY}

\begin{abstract}
The present work had the objective to elaborate the map of land use and vegetation covering from Tijuco river watershed, Ituiutaba-MG, based on digital images obtained by satellite from CBERS 2, through automatic delimitation of permanent preservation areas followed by identification of land use conflict based on the Brazilian Forest Code (Law $n^{\circ}$ 4771/1965) and National Council of Environment's Resolution $n^{-}$303/02. This paper analyzes, through quantitative parameters and the use of Geographic Information System, the maintenance tracks of width recommended by the legislation for permanent preservation areas over water bodies. The results showed a deficit of conserved areas along the riverbanks of 2334 ha that are not in compliance with the legislation. The pasture occupies unduly $0.97 \%$ of the area of the basin in the permanent preservation areas at the riverbanks, while agriculture occupies $0.38 \%$.
\end{abstract}

KEYWORDS: legal reserve, Geographic Information System - GIS, land use, remote sensing.

\section{INTRODUÇÃO}

A rápida expansão agrícola e o consequente desmatamento têm repercutido sobre os recursos hídricos e na qualidade de vida das populações, necessitando de uma reorganização do espaço e gerenciamento dos recursos naturais. A preservação e conservação da mata nativa, em específico aquelas situadas ao longo de cursos d'água e nascentes, têm ocupado destaque pela importância na proteção de recursos hídricos.

\footnotetext{
${ }^{1}$ Eng $^{\mathrm{o}}$ Agrícola, Prof. Doutor, Instituto Federal de Educação Ciência e Tecnologia do Triângulo Mineiro, IFTM, Uberaba - MG, renato@iftriangulo.edu.br.

${ }^{2}$ Eng ${ }^{\mathrm{a}}$ Agrônoma, Prof ${ }^{\mathrm{a}}$ Dra., FCAV/UNESP, Jaboticabal - SP, teresap@ fcav.unesp.br.

${ }^{3}$ Acadêmico do Curso de Tecnologia em Gestão Ambiental, Instituto Federal de Educação Ciência e Tecnologia do Triângulo Mineiro, IFTM, Uberaba - MG.

${ }^{4}$ Prof $^{-}$M.Sc., Instituto Federal de Educação Ciência e Tecnologia do Triângulo Mineiro, IFTM, Uberaba - MG, vlabdala@iftriangulo.edu.br. 
A preservação da vegetação natural nas margens dos rios e ao redor das nascentes e reservatórios, áreas de preservação permanente (APPs), conceituada como instrumento voltado para proteção de atributos ambientais em todo o território nacional, é regulamentado pelo código florestal brasileiro, Lei $\mathrm{n}^{\mathbf{0}}$ 4.771/1965, e a resolução CONAMA 303 (2002) estabelece a largura da área das APPs, conforme apresentado na Tabela 1. Recentemente, o código florestal tem sido amplamente discutido em diversos fóruns, como o Conselho Nacional de Meio Ambiente e o Congresso Nacional. Nessas discussões, buscou-se atualizá-lo, disciplinando a expansão agrícola sobre as florestas e demais vegetações nativas. Dessa forma, novas propostas sugerem a extinção das reservas legais e, em substituição, propõe o alargamento destinado à preservação permanente nas áreas marginais dos corpos d'água dos atuais 30 metros (para rios e córregos de até $10 \mathrm{~m}$ de largura) para 400 m (ROSSENER \& RANIERI, 2007).

TABELA 1. Largura da área de preservação permanente (APP) em função do tipo de corpo d'água. Width of the area of permanent preservation depending on the type of water bodies.

\begin{tabular}{cc}
\hline Largura do Canal de Drenagem & Largura da APP \\
\hline Até $10 \mathrm{~m}$ & $30 \mathrm{~m}$ em cada margem \\
de 10 a $50 \mathrm{~m}$ & $50 \mathrm{~m}$ em cada margem \\
de 50 a $200 \mathrm{~m}$ & $100 \mathrm{~m}$ em cada margem \\
de 200 a $600 \mathrm{~m}$ & $200 \mathrm{~m}$ em cada margem \\
superior a $600 \mathrm{~m}$ & $500 \mathrm{~m}$ em cada margem \\
\hline
\end{tabular}

As APPs são áreas cobertas ou não por vegetação nativa com função ambiental de preservar a paisagem, os recursos hídricos, a estabilidade geológica, a biodiversidade, o fluxo gênico de fauna e flora, proteger o solo e assegurar o bem-estar das populações humanas. Localizam-se nas margens dos rios, córregos, lagos, represas e outros corpos d'água em faixas de largura variável nas encostas íngremes, topos de morro, além de outros locais especificados pelo código florestal.

A degradação das matas ciliares contribui para o assoreamento, elevação da turbidez da água e para a erosão das margens dos cursos d'água, transportando substâncias poluidoras, como defensivos e fertilizantes agrícolas (OLIVEIRA FILHO et al., 1994).

Sendo a legislação ambiental brasileira ampla, vários fatores contribuem para torná-la pouco ágil e efetiva (CRESTANA et al., 1993). Diante desses fatores, as metodologias possíveis de serem implementadas utilizando os sistemas de informação geográfica (SIG) favorecem o processamento rápido e eficiente dos dados, gerando informação para o planejamento racional de uso e conservação do solo e da água (NASCIMENTO et al., 2005).

De acordo com TONELLO (2005), a bacia hidrográfica sendo conceituada como unidade de planejamento, o disciplinamento do uso e a ocupação do solo são os meios mais eficientes de controle dos recursos hídricos que a integram. Na gestão de bacias hidrográficas, a integração e a análise de um grande número de informações de forma convencional tornam-se difíceis e demoradas. Contudo, quando as informações são representadas espacialmente através de mapas, utilizando-se da ferramenta SIG, geram grande potencial de integração dos dados, subsidiando o gerenciamento de bacias (SANTOS, 2007).

A bacia hidrográfica do Rio Tijuco tem chamado a atenção de vários segmentos da sociedade local e regional, que atualmente inicia o processo de conscientização para o problema ambiental vigente, resultante dos impactos antrópicos. Sendo assim, torna-se necessário um alerta em relação aos impactos ambientais causados devido à redução da disponibilidade hídrica, decorrente da captação superficial, aos processos erosivos e consequente assoreamento dos corpos d'água.

O presente trabalho visa a delimitar e a quantificar as áreas de APPs relativas aos corpos d'água, comparando-as com o uso e ocupação atual do solo, identificando áreas de conflito de uso através da utilização do SIG, na bacia do Rio Tijuco, município de Ituiutaba - MG. 


\section{MATERIAL E MÉTODOS}

A bacia hidrográfica do Rio Tijuco, município de Ituiutaba, com área aproximada de $1.335,1 \mathrm{~km}^{2}$, região de grande significado econômico para o Estado de Minas Gerais, localiza-se no Triângulo Mineiro, entre as coordenadas geográficas $18^{\circ} 40^{\prime}$ e $19^{\circ} 47^{\prime} \mathrm{S}$ e $47^{\circ} 53^{\prime}$ a $50^{\circ} 13^{\prime} \mathrm{W}$. O Rio Tijuco nasce a $950 \mathrm{~m}$ de altitude, nas coordenadas $19^{\circ} 31^{\prime} 39,88^{\prime}$ ' S; 47 $54^{\circ} 41,40^{\prime \prime} \mathrm{W}$, no município de Uberaba - MG, e tem sua foz na cota de $526 \mathrm{~m}$, sendo afluente da margem esquerda do Rio Paranaíba, tendo como principais afluentes os rios Prata, Babilônia, Cabaçal, Douradinho, Panga, dentre outros.

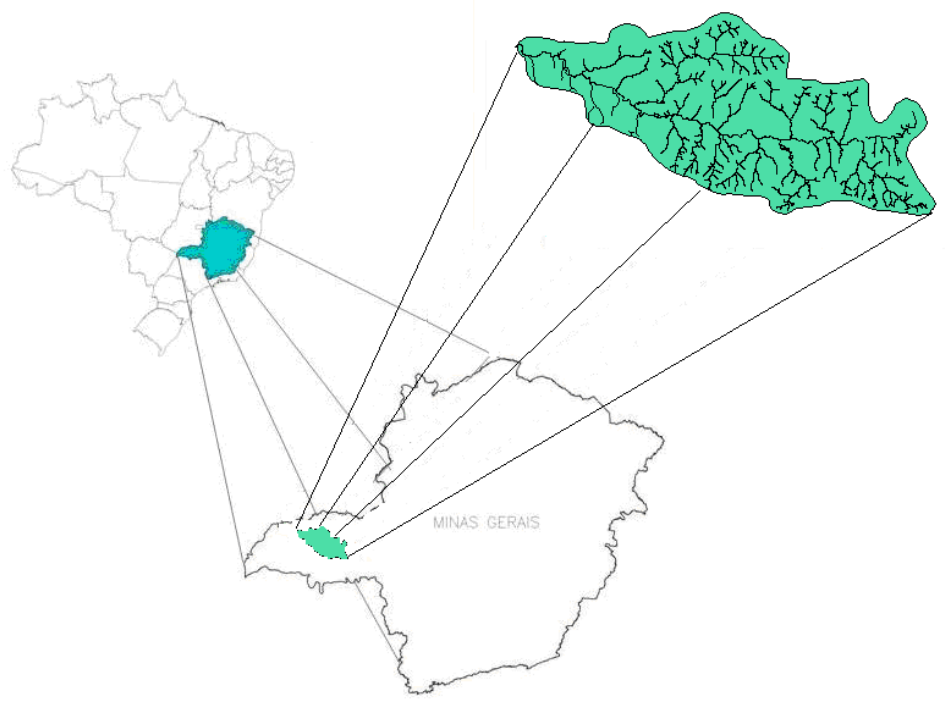

FIGURA 1. Localização da bacia hidrográfica do Rio Tijuco, Minas Gerais. Location of the Tijuco river watershed, State of Minas Gerais, Brazil.

O clima da região é do tipo tropical, com duas estações bem definidas, uma chuvosa de outubro a abril e outra seca de maio a setembro. A média pluviométrica oscila entre 1.300$1.700 \mathrm{~mm} \mathrm{ano}^{-1}$, onde $50 \%$ precipitam nos meses de novembro a fevereiro. Essa concentração da precipitação e a característica de chuvas muito intensas são fatores relevantes para a intensificação dos processos erosivos (SANTOS \& BACCARO, 2004). RIBEIRO (1997), citado por SANTOS \& BACCARO (2004), destacou que os totais anuais precipitados vão decrescendo para oeste, ao longo da calha do Rio Paranaíba, destacando a área entre Cachoeira Dourada e a foz do Rio Tijuco como sendo a menos chuvosa, com precipitações inferiores a $1.300 \mathrm{~mm}$ anuais.

Geologicamente, a bacia do Rio Tijuco está inserida na unidade do planalto do Brasil Central, em bacia sedimentar geotectônica denominada Bacia Sedimentar do Paraná. A área de estudo situa-se na porção norte/nordeste da Bacia Sedimentar do Paraná, apresentando estratigraficamente rochas do Grupo São Bento (basaltos da Formação Serra Geral) sobreposto pelos arenitos e conglomerados do Grupo Bauru (arenitos de Formação Uberaba e Formação Marília), com boa parte da área coberta com sedimentos cenozoicos (sedimentos aluviais recentes).

Para atingir o objetivo proposto neste trabalho, foi necessária a criação de um banco de dados georreferenciado com arquivos e imagens representando planos de informação de interesse a partir dos mapas rede de drenagem e uso e ocupação do solo. Os softwares utilizados para a criação do banco de dados georreferenciado, tratamento e análise dos dados espaciais e visualização de imagens foram o IDRISI ANDES e o ENVI 4.

Na obtenção dos planos de informação da rede de drenagem e uso e ocupação do solo, foi utilizado mosaico de imagens orbitais do sensor CCD do satélite CBERS 2 (China-Brazil EarthResources Satellite), cujas imagens datam de 27 de junho de 2008, obtidas junto ao INPE (Instituto Nacional de Pesquisas Espaciais) em escala de resolução aproximada 1:50.000, onde, após composição de bandas (3R,4G,1B) efetuada no ENVI 4, possibilitou-se a vetorização da rede de 
drenagem da bacia do Rio Tijuco. Posteriormente, extraiu-se a informação de uso e de ocupação dos solos, visando a diagnosticar principalmente a cobertura vegetal presente na bacia, utilizando a técnica de classificação supervisionada de imagens, utilizando o classificador de Máxima Verossimilhança (MAXLIKE) do Software IDRISI ANDES, mostrando a situação atual de ocupação do solo, especificamente a identificação da cobertura vegetal.

De posse do mapa rede de drenagem, procedeu-se à análise dimensional e a classificação da largura dos rios determinadas através do software GOOGLE EARTH, onde, posteriormente, utilizando o software AUTOCAD, foram locados em planos de informação diferenciados de acordo com a largura da calha dos rios, determinando 3 classes: rios menores que $10 \mathrm{~m}$, rios medindo entre 10 e $50 \mathrm{~m}$ e rios entre 50 e $200 \mathrm{~m}$.

Para a obtenção do plano de informação das APPs recomendadas ao longo dos cursos d'água, procedeu-se à importação das classes das redes de drenagem subdivididas, em função da largura da calha do rio, do AUTOCAD para o IDRISI. O plano de informação rede de drenagem foi convertido do formato vetorial (vector) para o formato matricial (raster), elaborada no IDRISI ANDES, onde, utilizando-se do comando BUFFER, calculou-se a distância euclidiana a partir do mapa das redes de drenagem. Cada pixel assumiu um valor de distância, sendo o buffer de $30 \mathrm{~m}$ para os cursos de águas menores de $10 \mathrm{~m}$ de largura, buffer de $50 \mathrm{~m}$ para os cursos de $10 \mathrm{a} 50 \mathrm{~m}$, e buffer 100 entre 50 a $200 \mathrm{~m}$, para cada lado das margens das redes de drenagem das microbacias, de acordo com o que prescreve a resolução CONAMA n⿳o 303 (2002) e Código Florestal (Lei $\mathrm{n}^{\mathrm{o}}$ 4.771/1965 alterada pela Lei $\mathrm{n}^{\mathrm{o}}$ 78.003/1989) (Figura 2).

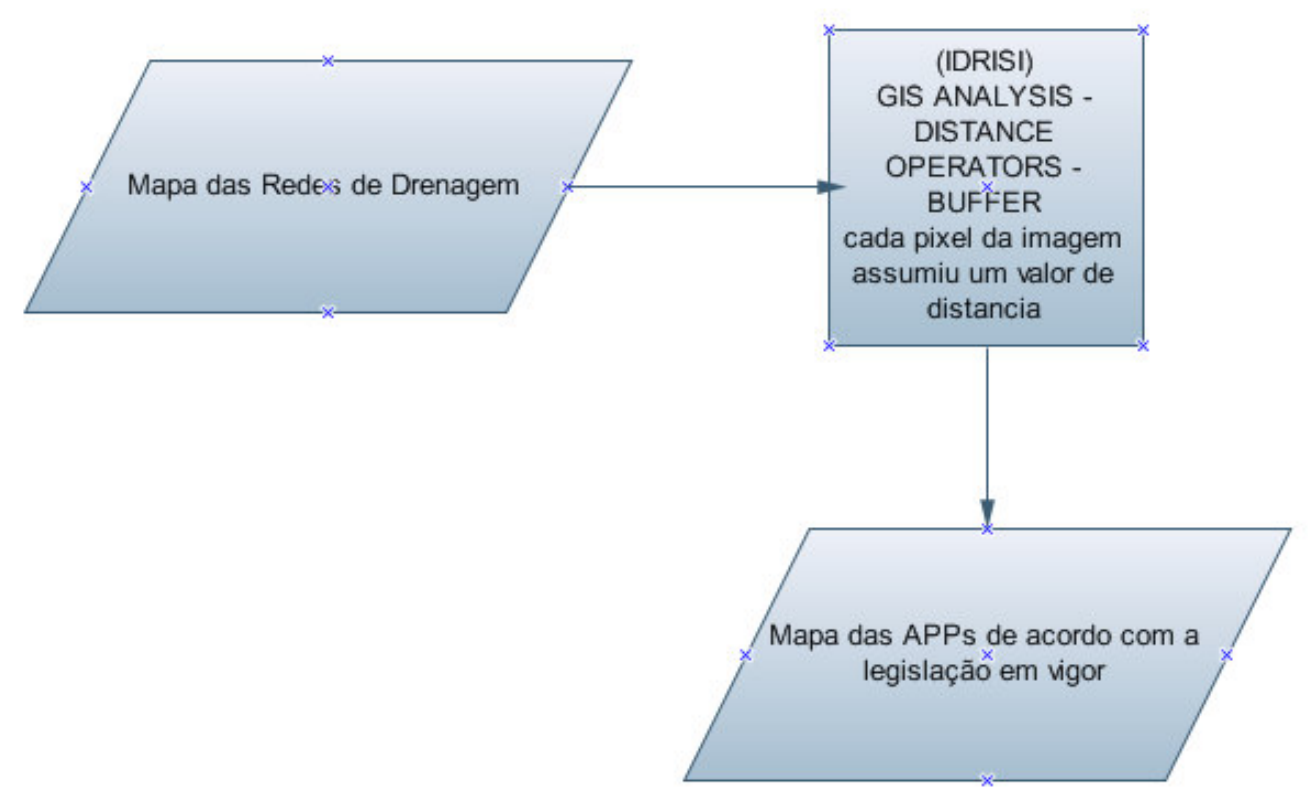

FIGURA 2. Metodologia para a confecção do mapa APPs recomendadas de acordo com a legislação. Methodology for preparation of APP map recommended in accordance with the law.

Para a identificação das áreas de conflitos de uso nas APPs, foi executada uma operação de sobreposição dos mapas de uso e ocupação versus APPs recomendadas. Utilizando o comando CROSSTAB do IDRISI, separaram-se as classes de ocupação correlacionadas com as APPs recomendadas, conforme a legislação (Figura 3). 


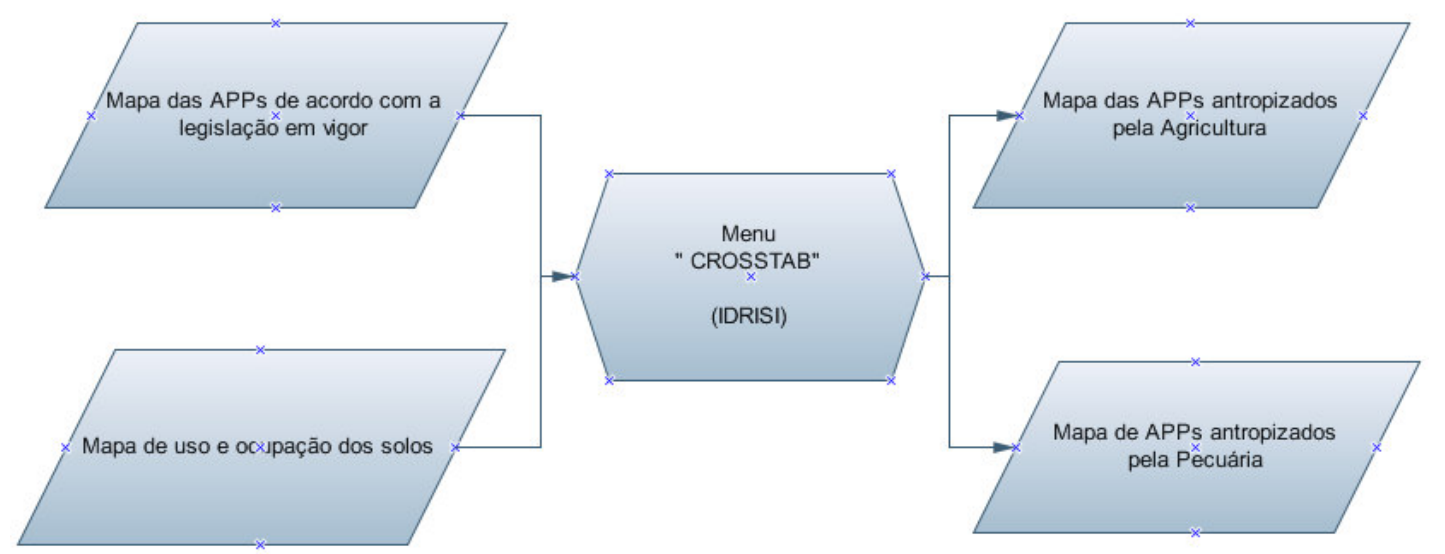

FIGURA 3. Metodologia para confecção dos mapas de APPs antropizados pela agricultura e pecuária. Methodology for preparation of maps of APP anthropic by agriculture and livestock.

Todos os mapas elaborados adotam o sistema de projeção Universal Transversa de Mercator (UTM), fuso 22, datum planimétrico WGS84 (World Geodetic System 1984).

\section{RESULTADOS E DISCUSSÃO}

$\mathrm{Na}$ área total da bacia, verifica-se que a agricultura ocupa 18,84\% da área, pecuária $57,02 \%$ e a vegetação nativa $21,42 \%$ (Figura 4), enquanto a cidade representa $1,80 \%$ e os rios e lagos $0,92 \%$, conforme Tabela 2.

TABELA 2. Percentagem de uso e ocupação da bacia. Percentage of land use and occupation at the watershed.

\begin{tabular}{lcc}
\hline Uso e Ocupação & Área (ha) & Percentagem da Área da Bacia (\%) \\
\hline Agricultura & 25.157 & 18,84 \\
Pecuária & 76.121 & 57,02 \\
Vegetação nativa & 28.594 & 21,42 \\
Cidade & 2.405 & 1,80 \\
Rios e lagos & 1.233 & 0,92 \\
\hline Total & 133.510 & 100,00 \\
\hline
\end{tabular}

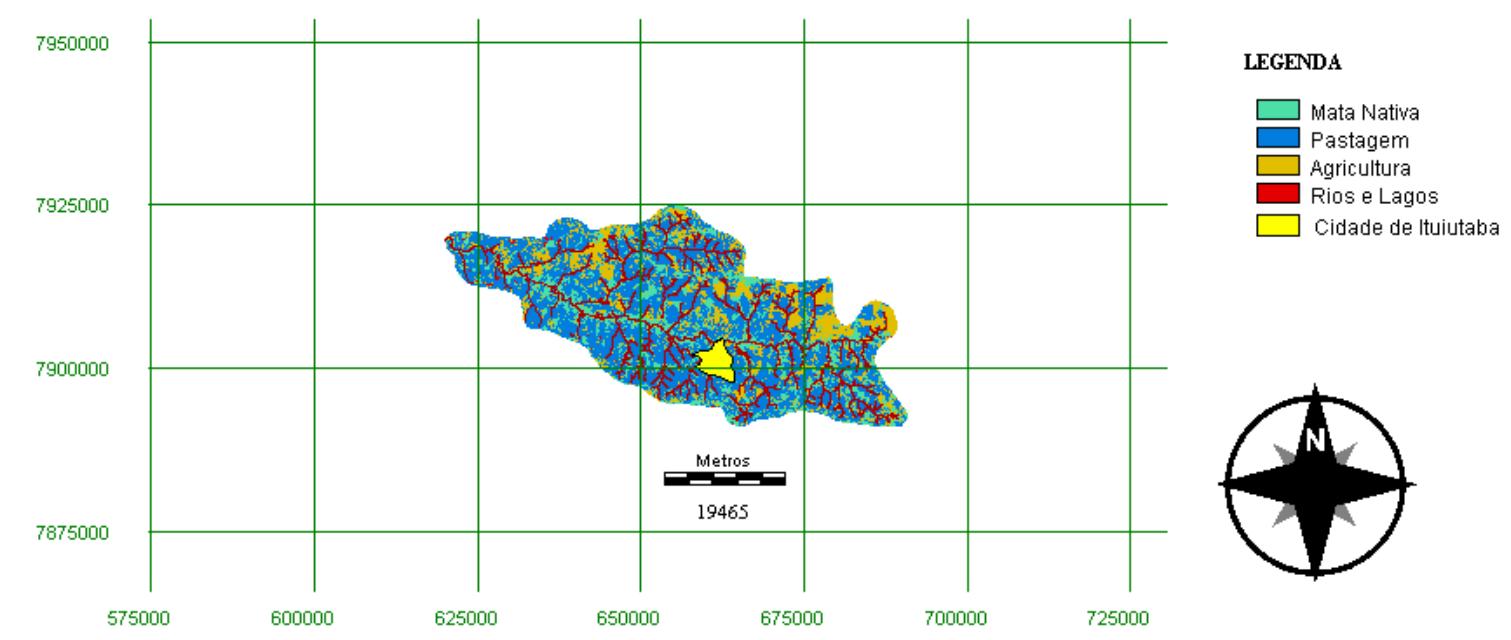

FIGURA 4. Uso e ocupação do solo na bacia do Rio Tijuco, município de Ituiutaba - MG. Land use and occupation at the Tijuco river watershed, State of Minas Gerais, Brazil. 
As APPs recomendadas ao longo dos cursos d'água no município de Ituiutaba totalizaram 5.144 ha, correspondendo a aproximadamente 3,85\% de sua área total e que, segundo prevê o Código Florestal Brasileiro, deve ser mantida intacta (Figura 5). De acordo com RIBEIRO et al. (2005), a delimitação automática das APPs elimina a subjetividade nos procedimentos de campo e viabilizam o fiel cumprimento do Código Florestal Brasileiro, favorecendo a fiscalização ambiental.

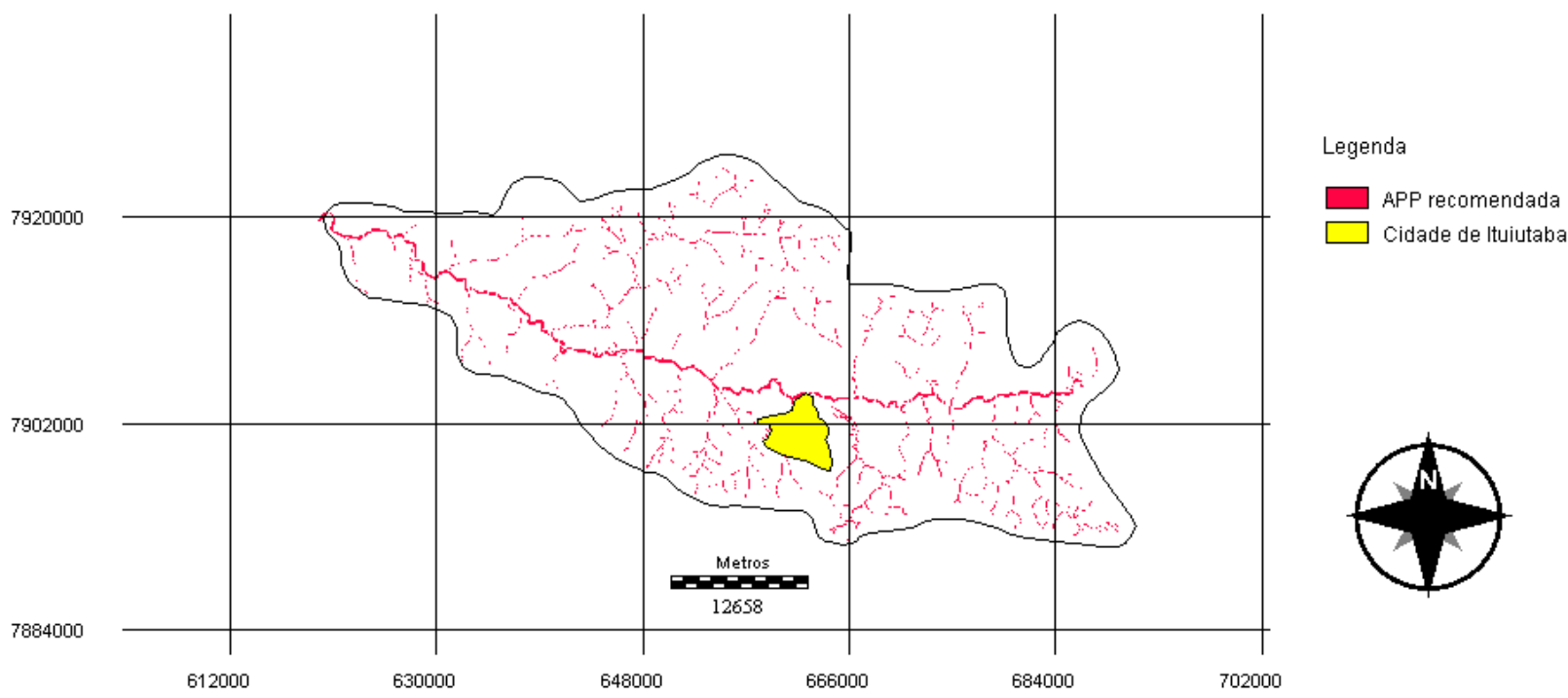

FIGURA 5. APPs recomendadas de acordo com legislação, para o município de Ituiutaba - MG. APP recommended in accordance with the law, for the city of Ituiutaba - MG.

A recomposição da mata ciliar da bacia do Rio Tijuco, no município de Ituiutaba, atendendo à legislação ambiental, é de 2.584 ha, sendo necessário, portanto, o reflorestamento em 2.334 ha com espécies nativas produzidas em viveiro florestal (Figura 6). As matas ciliares atuam como barreira física, regulando os processos de troca entre os ecossistemas terrestres e aquáticos, favorecendo a infiltração da água no solo e reduzindo significativamente a contaminação dos cursos d'água (KAGEYAMA, 1986; FERREIRA \& DIAS, 2004).

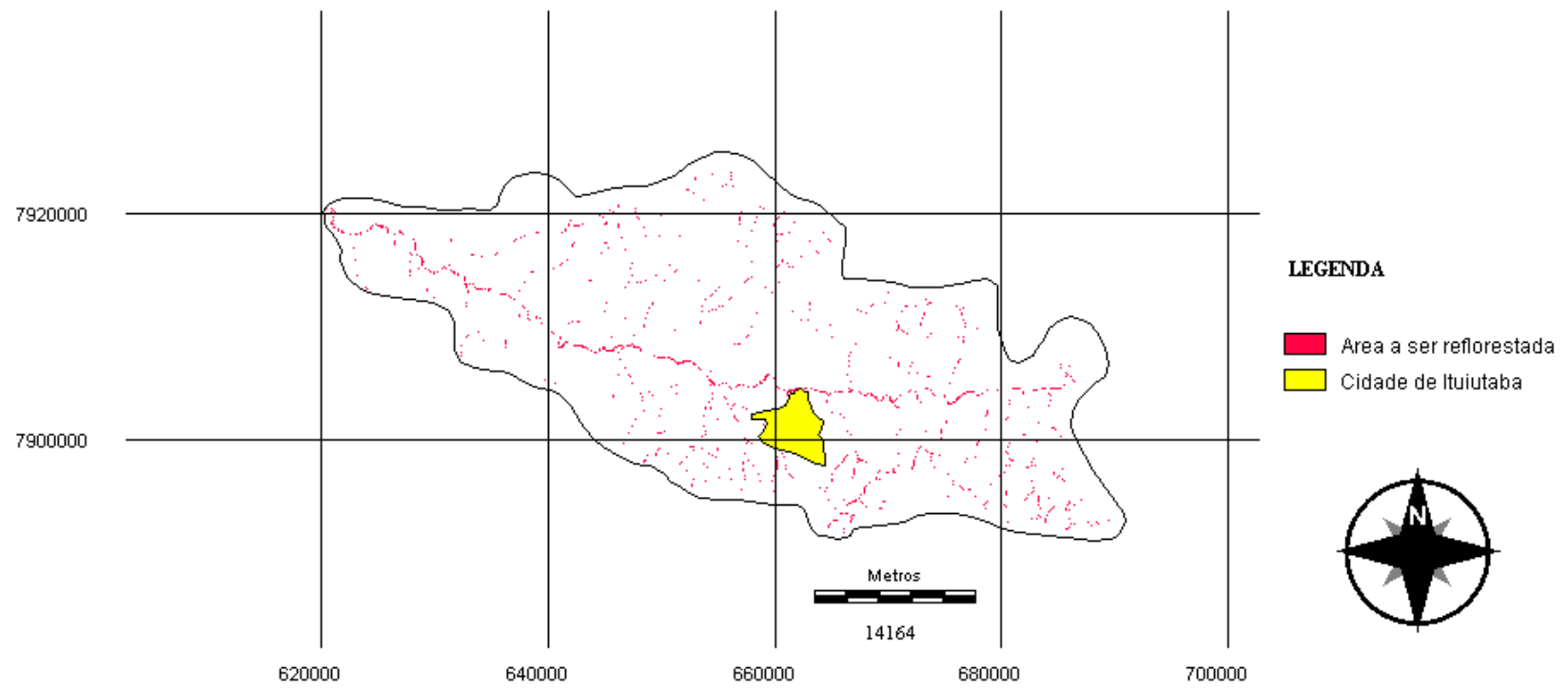

FIGURA 6. Área a ser reflorestada na bacia do Rio Tijuco, município de Ituiutaba. Area to be reforested at the Tijuco river watershed, city of Ituiutaba. 
Nas áreas de APPs que margeiam as calhas dos rios, a atividade agrícola ocupa 507 ha, a pastagem 1.291 ha e os 536 ha restantes estão desmatados, o que desrespeita a legislação ambiental (Figura 7).

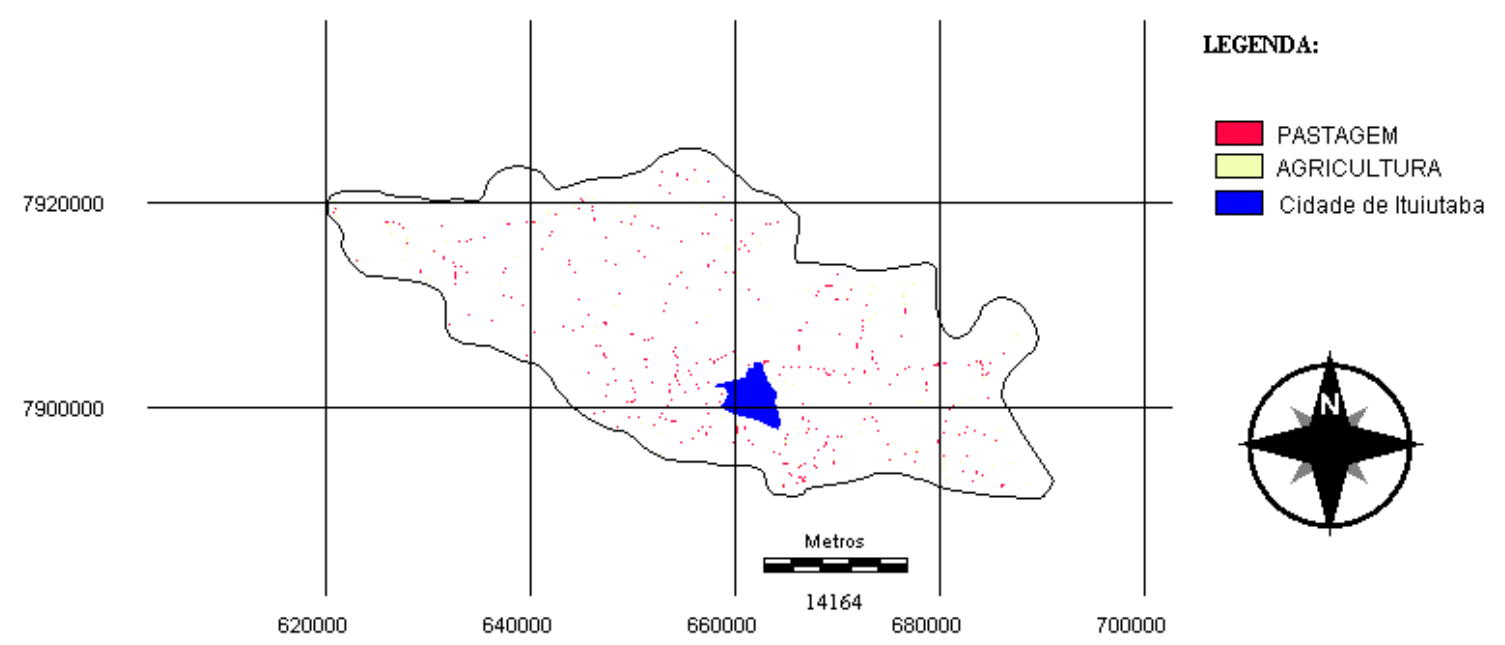

FIGURA 7. Áreas degradadas por agricultura e pastagem em APPs, na bacia do Rio Tijuco, município de Ituiutaba Degraded areas for agriculture and pasture in APP at the Tijuco river watershed, city of Ituiutaba.

A cobertura vegetal nativa que não margeia a calha das redes de drenagem totaliza 26.010 ha, correspondendo a 18,48\% da área total do município (Figura 8). Dessa forma, a área total com mata nativa dentro e fora das APPs, no município de Ituiutaba, as coberturas vegetais remanescentes apresentam proporções próximas aos $20 \%$ preconizados pelo código florestal, como observado na análise da Tabela 3.

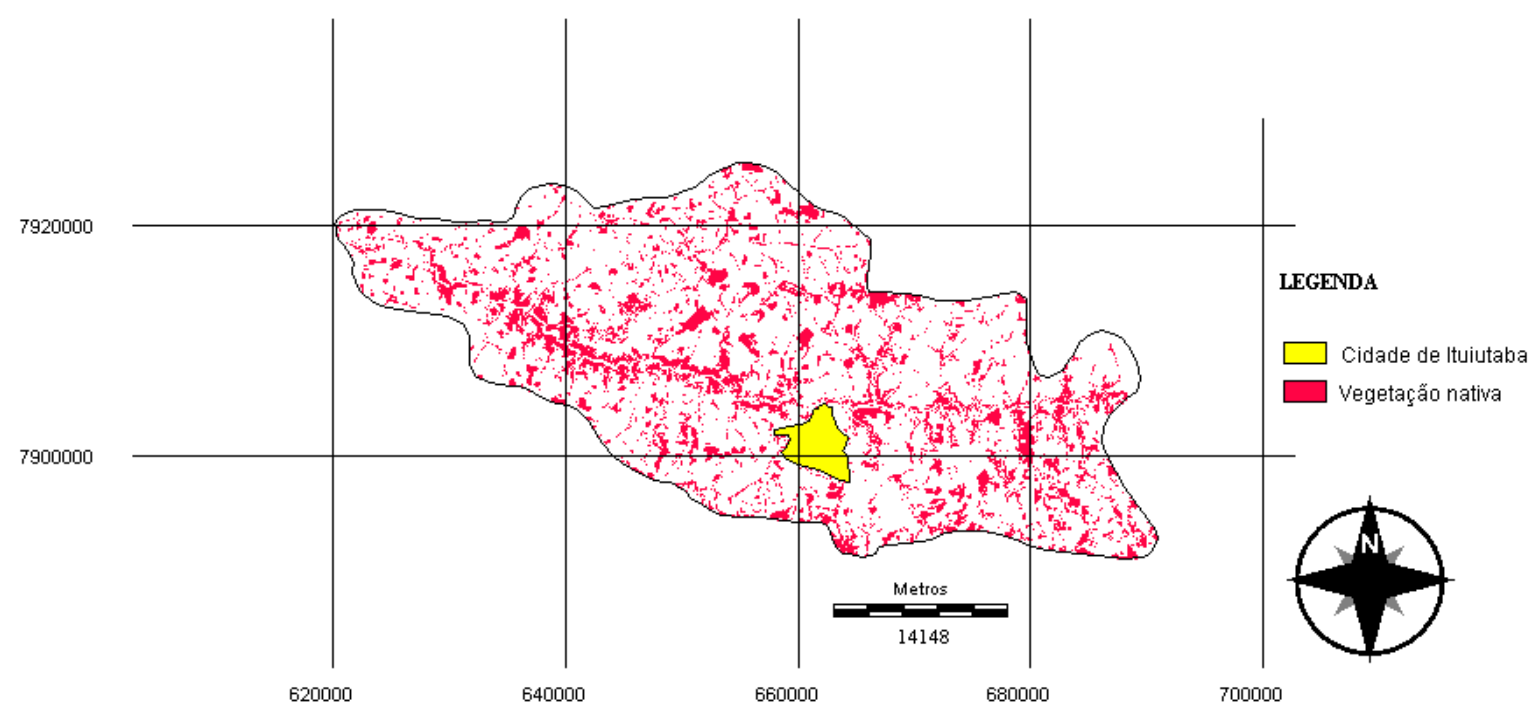

FIGURA 8. Vegetação nativa fora da área de APP na bacia do Rio Tijuco, município de Ituiutaba. Native vegetation outside the APP area at the Tijuco river watershed, city of Ituiutaba. 
TABELA 3. Área coberta por vegetação nativa remanescente. Covered area by remaining native vegetation.

\begin{tabular}{lcc}
\hline Vegetação Nativa Remanescente & Área (ha) & Percentagem da Área da Bacia (\%) \\
\hline Dentro de APP & 2.584 & 1,94 \\
Fora de APP & 26.010 & 19,48 \\
\hline Total & 28.594 & 21,42 \\
\hline
\end{tabular}

\section{CONCLUSÕES}

A adoção do SIG permite a delimitação automática das áreas de APPs e a identificação de conflitos de usos na bacia do Rio Tijuco.

$\mathrm{Na}$ região de estudo, observa-se um déficit de áreas conservadas às margens dos rios de 2.334 ha quanto à vegetação nativa em relação ao exigido pelo código ambiental vigente.

A atividade pecuária ocupa, indevidamente, $0,97 \%$ da área da bacia, em APPs às margens dos rios, enquanto a agrícola, $0,38 \%$.

\section{REFERÊNCIAS}

BRASIL. Leis e Decretos. Lei Federal no ${ }^{\text {4.771, de }} 15$ de setembro de 1965. Código Florestal Brasileiro. Brasília, 2002.

CONAMA. Resolução n⿳ 303, de 20 de março de 2002. Dispõe sobre parâmetros, definições e limites de Áreas de Preservação Permanente. Brasília, 2002.

CRESTANA, M.S.M.; TOLEDO FILHO, D.V.; CAMPOS, J.B. Florestas: sistemas de recuperação com essências nativas. Campinas: Coordenadoria de Assistência Técnica Integral, 1993. 60 p.

FERREIRA, D.A.C.; DIAS, H.C.T. Situação atual da mata ciliar do Ribeirão São Bartolomeu em Viçosa-MG. Revista Árvore, Viçosa, v.28, n.4, 2004. Disponível em:

$<$ http://www.scielo.br/scielo.php?script=sci_arttext\&pid=S010067622004000400016\&lng=\&nrm=i so>. Acesso em: 7 nov. 2008.

KAGEYAMA, P.Y. Estudo para implantação de matas de galeria na bacia hidrográfica do Passa Cinco, visando à utilização para abastecimento público. Piracicaba: Universidade de São Paulo, 1986. 236 p. Relatório de Pesquisa.

NASCIMENTO, M.C. do; SOARES, V.P.; RIBEIRO, C.A.A.S.; SILVA, E. Uso do Geoprocessamento na identificação de conflito de uso da terra em áreas de preservação permanente na bacia hidrográfica do Rio Alegre, Espírito Santo. Ciência Florestal, Santa Maria, v.15, n.2, 2005. Disponível em: http://www.ufsm.br/cienciaflorestal/artigos/v15n2/A10V15N2.pdf. Acesso em: 14 nov. 2008.

OLIVEIRA-FILHO, A.T.; ALMEIDA, R.J. de; MELLO, J.M. de; GAVILANES, M.L. Estrutura fitossociológica e variáveis ambientais em um trecho de mata ciliar do Córrego Vilas Boas, Lavras (MG). Revista Brasileira de Botânica, São Paulo, v.17, n.1, p.67-85, 1994.

RIBEIRO, A.G.; ARANTES, A.O.; MACEDO, D.; FRANCO, J.B.S. O papel dos recursos hídricos na sustentabilidade do sistema agroalimentar no domínio dos cerrados do Brasil Central. Estudo de caso: a bacia do médio/baixo Paranaíba no Estado de Minas Gerais. In: SHIKI, S.; GRAZIANO DA SILVA, J.; ORTEGA, A.C. Agricultura, meio ambiente e sustentabilidade do cerrado brasileiro. Uberlândia: UFU-EMBRAPA-UNICAMP, 1997. p.372.

RIBEIRO, C.A.A.S.; SOARES, V.P.; OLIVEIRA, A.M.S.; GLERIANI, J.M. O desafio da delimitação de áreas de preservação permanente. Revista Árvore, v.29, n.2, p.203-212, 2005. Disponível em: http://dx.doi.org. DOI: 101590/S100-676220050002000004. 
ROSSENER, R.R.S.; RANIERI, V.E.L. Influência da aplicação das faixas de preservação permanente sobre a estrutura da paisagem: Estudo exploratório na região de Ribeirão Preto - SP utilizando ferramentas de geoprocessamento. Minerva. São Carlos, v.4, n.1, 2007. Disponível em: <http://www.fipai.org.br/Minerva\%2004(01)\%2008.pdf>. Acesso em: 17 nov. 2008.

SANTOS, L.; BACCARO, C.A.D. Caracterização geomorfológica da bacia do Rio Tijuco. Caminhos de Geografia, Uberlândia, v.5, n.11, 2004. Disponível em :

$<$ http://www.caminhosdegeografia.ig.ufu.br/include/getdoc.php?id=306\&article=80\&mode=pdf $>$. Acesso em: 17 nov. 2008.

SANTOS, S.B. dos. Análise do uso e ocupação do solo de áreas de preservação permanente utilizando ferramentas do SIG na gestão de bacias hidrográficas: o caso da bacia hidrográfica do Ribeirão São Lourenço. 2007. 84 f. Dissertação (Mestrado em Ciências em Engenharia da Energia) - Universidade Federal de Itajubá, Itajubá, 2007. Disponível em:

<http://200.131.186.194/phl/pdf/0032111.pdf>. Acesso em: 10 nov. 2008.

TONELLO, K.C. Análise hidroambiental da bacia hidrográfica da Cachoeira das Pombas, Guanhães - MG. 2005. 69 f. Dissertação (Mestrado em Ciência Florestal) - Universidade Federal de Viçosa, Viçosa - MG, 2005. 